\title{
Potential uses of xylanase-rich lignocellulolytic enzymes cocktail for Oil Palm Trunk (OPT) degradation and lignocellulosic ethanol production
}

\begin{abstract}
In this paper, we reported that oil pam trunk (OPT) can be used as an alternative fermentation feedstock for lignocellulolytic enzyme production and carbon source for bioethanol production. Xylanase production from OPT by locally isolated fungus, Aspergillus fumigatus SK1, under solid-state fermentation (SSF), was optimized using central composite design (CCD). Under optimized conditions, a maximum xylanase activity of $1792.43 \mathrm{U} / \mathrm{g}$ was produced, which was 4.28-fold higher than before optimization. Significant amounts of CMCase $(56.19 \mathrm{U} / \mathrm{g})$, FPase $(3.47 \mathrm{U} / \mathrm{g})$, and $\beta$-glucosidase $(1.55 \mathrm{U} / \mathrm{g})$ were also found concomitantly with xylanase. Subsequently, the effect of solid loading, Tween-80 concentration, and incubation temperature on the saccharification of OPT by the crude enzymes were optimized to enhance the total reducing sugar production. A total of 13.148 $\mathrm{g} / \mathrm{L}$ of reducing sugar was reported under optimized conditions. Comparisons of physiochemical characteristics between native and hydrolyzed OPT via scanning electron microscopy (SEM), Fourier transform infrared (FTIR) spectroscopy, and X-ray photoelectron spectroscopy (XPS) showed strong degradation capacity of the crude enzymes toward cellulose, hemicellulose, and lignin. Alcoholic fermentation of the hydrolysate by Candida tropicalis RETL-Crl produced $3.067 \mathrm{~g} / \mathrm{L}$ of ethanol. Higher ethanol production at $0.322 \mathrm{~g} / \mathrm{g}$ with a theoretical ethanol yield of $68.05 \%$ indicates that Candida tropicalis RETL-Crl has a greater potential to be used in ethanol fermentation process. This result further proved that OPT has the potential to be used as a renewable carbon source.
\end{abstract}

Keyword: Fourier transform infrared (FTIR); Lignocellulolytic enzyme 